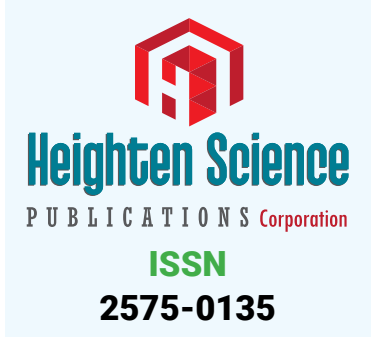

*Address for Correspondence: Sunil Kumar Mukherjee, Division of Plant Pathology, IARI, New Delhi, India, Tel: +91-9871995629; 011-2584-3588; Fax: 011-2584-0772; Email: sunilmukherjeeudsc@gmail.com

Submitted: 27 December 2018

Approved: 24 January 2019

Published: 25 January 2019

Copyright: @ 2019 Gupta D, et al. This is an open access article distributed under the Creative Commons Attribution License, which permits unrestricted use, distribution, and reproduction in any medium, provided the original work is properly cited

Check for updates
Commentary

\section{Antiviral RNAi mediated Plant defense versus its suppression by viruses}

\author{
Dinesh Gupta ${ }^{1}$ and Sunil Kumar Mukherjee ${ }^{2 *}$ \\ ${ }^{1}$ Translational Bioinformatics Group, ICGEB, New Delhi, India \\ ${ }^{2}$ Division of Plant Pathology, IARI, New Delhi, India
}

\section{Abstract}

The age-old battle between plants and viruses has many twists and turns. Plants acquired the RNAi factors to checkmate the viruses and the viruses encode VSRs to defeat RNAi for their own survival. Plants designed mechanisms to neutralize the toxic effects of VSRs and the viruses, in their turn, use host microRNAs to strengthen their infection processes. The infightings between these two entities will take different shapes with prolonged evolution and accordingly the researchers will dig these novel forms of duels not only to throw lights in the involved mechanisms but also to manipulate various antiviral strategies. Some of the research courses that might come up in the immediate future are discussed.

The arms race between host and virus is a continually evolving process involving multiple layers of interactions. Most of all eukaryotic organisms are RNAi-competent and defend themselves against the intruding molecular parasites, namely Viruses and Transposons [1]. As a reaction to host-defense (or rather counterdefence), viruses have also generated multiple weapons in their armory. The hosts in turn tighten up their security by developing means of counter-counterdefence. Viruses also reciprocate and invent strategies to weaken the hosts in subsequent rounds. All plant viruses encode RNAi-suppressors (VSRs) and use them to battle the host RNA-factors to uphold their counter-defense [2]. The VSRs are deactivated by hosts by mechanisms known as counter-counter defense. Following viral invasion in plants, host-microRNA (miR) profiles undergo a lot of changes [3]. A subset of these deregulated miRs likely works against viral invasion, multiplication and systemic propagation [4,5]. However, recent reports indicate that some of the virus-induced miRs are also used to sensitise the host for enhancing viral invasion. Of the latter category, we would like to choose only three miRs, namely miR168, miR6026 and miR319 here as the representative candidates for their ability to sustain viral growth. There are other miRs who also work in similar pathway but we have chosen the above three because of the preponderance of literature reports.

Following entry of viruses in the plant cell, ds-RNA intermediates of viral genomes; viral transcripts etc. are generated due to various reasons like viral genome replication/ transcription, convergent transcriptions from viral genomes or hosts' RNA dependent RNA Polymerases activities on the viral transcripts etc. These dsRNAs are diced by DCLs to produce small RNAs which are known as V-siRNAs [6]. The V-siRNAs are further amplified by host-dependent processes and are known as secondary V-siRNAs or Va-siRNAs [7]. These V-siRNAs, along with Va-siRNAs, either slice or translationally inhibit the viral mRNAs in RISC mediated processes and eventually reduce the virus titer [8]. Various host factors work in this host-defense pathway and are known as antiviral RNAi factors. The core defense factors include RDRs (mostly RDR6, RDR2, RDR1), DCLs (mostly DCL4, followed by DCL2), and AG0 proteins (AG01, AGO2, AG03, AGO4, 
AGO5, AG07, AG010 etc.). A list of these factors in arabidopsis and rice are shown in table 1. Generally, DCL4 is the major producer of V-siRNA with DCL2 playing the second fiddle. However, there are few instances where DCL2 plays the major role over DCL4, for example, the patho-system of Tomato Mosaic Virus (ToMV) and tomato [9]. DCL3 also participates in case of viruses with single-stranded DNA genomes, namely begomoviruses, to transcriptionally silence the viral DNA genome [10]. The v-siRNAs of three different sizes $(21 / 22 / 24 \mathrm{bps})$ spread from the source of production to distant non-infected cells in systemic fashions and thus protect the distant cells against incoming viral invasion. This systemic activity is facilitated by DCL2 while DCL4 plays the antagonistic inhibitory role [11,12]. In addition to the core factors, a few other accessory antiviral factors have recently been screened genetically and are listed in table $2[13,14]$. Besides the V-siRNAs, the deregulated host miRs caused by viral invasions also play antiviral roles [5]. A set of plant miRs have been bioinformatically postulated that retain the ability to silence viral ORFs, and only a couple of them have been validated experimentally [4]. Plum pox virus (PPV) chimeras harbor plant miRNA target sequences and these are functional in Arabidopsis, and were also silenced by miRNA function in three different host plants [15]. Some tomato miRs are also known to produce phasiRNAs with antiviral activity [9]. The generations of the 21-nuclotide phasiRNAs are initiated by the action of DCL2-made 22-mer miRs on several diseaserelated genes; and factors like DCL4, together with AG01, AGO4, AGO7, SUPPRESSOR OF GENE SILENCING3 (SGS3), RDR6, and DOUBLE-STRANDED RNA BINDING FACTOR 4 (DRB4) etc. are involved in different steps of phasiRNA synthesis [16].

Viruses have also evolved to defeat the antiviral RNAi pathways, mostly by encoding proteins from their genomes that are known as RNAi suppressors. These suppressors not only counteract host defense but also participate in other pathways necessary for the viral life cycle. These are very important for viral replication and

\begin{tabular}{|c|c|c|c|}
\hline \multicolumn{2}{|c|}{ Arabidopsis } & \multicolumn{2}{|r|}{ Rice } \\
\hline Genes & Pairing miRs & Genes & Pairing miRs \\
\hline DCL1 & $\begin{array}{l}\text { miR162-3P } \\
\text { miR166-5P }\end{array}$ & DCL1 & miR162, miR166-5P \\
\hline DCL2 & - & DCL2 & - \\
\hline DCL3 & \multirow[t]{2}{*}{-} & DCL3a & miR2907, miR812 \\
\hline & & DCL3b & miR531, miR168 \\
\hline DCL4 & - & DCL4 & miR396, miR1858, miR396 \\
\hline AG01 & $\begin{array}{c}\text { miR168-5P } \\
\text { miR8181 }\end{array}$ & AG01 & miR168, miR531, miR1846-3P, miR5075 \\
\hline AGO2 & - & AGO2 & miR6246, miR1437-3P, miR1846, miR5075 \\
\hline AGO3 & miR403 & - & \\
\hline AGO4 & - & - & \\
\hline AG05 & - & - & \\
\hline AG07 & miR854, miR162 & - & \\
\hline AG010 & miR168, miR5658 & - & \\
\hline- & - & AG018 & miR168, miR2091-5P \\
\hline RDR1 & $\operatorname{miR} 5020$ & RDR1 & miR531, miR1876, miR166 \\
\hline RDR2 & - & RDR2 & miR1437-3P \\
\hline RDR6 & - & RDR6 & - \\
\hline
\end{tabular}

Table 2: Recently discovered accessory antiviral RNAi factors

\begin{tabular}{|c|c|c|c|}
\hline & Arabidopsis & \multicolumn{2}{c|}{ Rice } \\
\hline Genes & Pairing miRs & Genes & Pairing miRs \\
\hline ALA1 & - & ALA1 & - \\
\hline ALA2 & - & ALA2 & miR1851 \\
\hline AVi2 & - & AVi2 & - \\
\hline
\end{tabular}

The free energy of pairing between mRNA and miR for every event was less than $-30 \mathrm{~K} \mathrm{cal} / \mathrm{mol}$. The MiRanda program was used to predict the miRs. 
systemic spread and are crucial for disease expression [17]. Almost all plant viruses encode RNAi suppressors and a multitude of these have been cloned and characterized in large numbers. The structures and functions of a few of them are already known in atomistic details [18]. However, there are no common motifs known so far but a subset of them has 'GW' repeats in their peptide sequences and these are used mostly to inactivate the AGO proteins of the host [19]. The suppressors from various viral genera participate in almost every steps of RNAi activity, starting from generation of double-stranded viral RNA to either slicing or translationally repressing viral mRNAs. A majority of suppressors are involved in ds-RNA or si-RNA binding and protect them from downstream RNAi activity [20]. In this way, they block either biogenesis or functions of V-siRNA. They also cause expression of host miRs and alter their activities [21]. The various mechanisms of antiviral RNAi suppression have been discussed in many recent reviews $[4,18]$. However, a couple of recent discoveries are worth mentioning. When Peanut clump virus enters host cells, v-siRNAs of size 22- mer and 21-mer are generated from everywhere of the viral genome by usual mechanisms. But the viral P15 RNAi suppressor binds very strongly to the 22-mer V-siRNAs and does not allow them to load on RISC complex, thus inactivating the functions of those V-siRNAs. However, the binding to 21-mer V-siRNA is weak and following binding, the siRNAs are transported to the peroxysomes because of PTS targeting signal of P15. In this way, the systemic spread of V-siRNAs is inhibited so that the viral spread to the neighboring cells can occur without interruptions [22]. In this way, P15 carries out its intracellular and intercellular activities to weaken the host defense and promote viral infection. In another example, a potyvirus, namely Turnip mosaic virus (TuMV) has been allowed to infect Nicotiana benthamiana plant and the viral RNA has been found to be subjected to both antiviral silencing and RNA decay pathways. However, the two viral suppressors, namely Hc-Pro and VPg, interact with host XRN4 and DCP2 respectively and compromise the antiviral function [23].

When the viral suppressors tend to debilitate the host antiviral defense, the hosts also should be sensing lack of security and mount a reaction against it to augment its security measures. And the hosts perform that job that efficiently using various means which could be collectively called as 'counter-counterdefence'. The " $R$ " genes of host protect the plant against viruses but the unregulated expression of those genes also causes a toll on the plant growth potential. Hence under the normal conditions when there are no viral invasions, these genes are kept controlled by post-transcriptional gene silencing (PTGS), effected by DCL4-dependent 21-mer phasiRNAs that act in both cis and trans-acting manners. For example, the transcripts of $\mathrm{N}$ gene of tobacco that resist TMV are sliced by two microRNAs, namely nta-miR6019 (22-mer) and ntamiR6020 (21-mer) and eventually the phasiRNAs are made by usual procedures; and these phasiRNAs keep the $\mathrm{N}$ gene expression under control. But the PTGS control is compromised in presence of the viral RNAi suppressors, causing over-expression of the R genes to protect the host against viral invasion [24]. In another study with Sugarcane Mosaic Virus (SCMV)- infection in maize, a host protein has been found to interact specifically with the RNAi-suppressor of the virus. The violaxanthin deepoxidase protein of maize (Zea mays), ZmVDE binds with HC-Pro of SCMV and this interaction down-regulates the RNA silencing suppression activity of HC-Pro. This down-regulation results in reduced accumulation of viral RNA and coat-protein in the infected cell [25]. Examples can also be drawn from geminivirus infection in tobacco cells. Both tobacco and tomato can be infected by Tomato Yellow Leaf Curl China Virus (TYLCCV) and the virus carries its satellite DNA, named beta-DNA with it. The protein encoded by beta-C1 is an RNAi suppressor and a known pathogenicity determinant. The host protein, namely, tobacco RING E3 ligase protein designated NtRFP1 is found to interact with beta-C1, causing ubiquitination of the latter one. Thus beta-C1 gets proteosomally degraded resulting in attenuation of viral disease symptoms [26]. There is another well-known plant protection phenomenon named as Systemic Acquired 
Resistance (SAR) which is salicyclic acid mediated and protects plants against the secondary infection of a broad range of pathogens. During the SAR-response against the Cucumber Mosaic Virus (CMV) in tobacco, the tobacco calmodulin-like protein, rgs-CaM is induced, which in turn interacts with CMV-2b protein that acts an RNAisuppressor of the virus. This interaction leads to degradation of CMV-2b via autophagy and the tobacco plant receives protection against the biotic stress of CMV [27]. Thus there are many counter-counter defense mechanisms used by hosts to checkmate viral pathogens.

The co-evolutionary theory of arms race between host and virus predicts that the counter-counter suppression of antiviral RNAi response of host will be matched by the efficient response from the viruses. The viruses etch out that response using the novel means. The host microRNA profiles change quite a bit following viral invasions and a subset of the induced microRNAs are used for the betterment of viral invasion processes. We would illustrate these events taking three candidate miRs as representatives, namely miR168, mir6026 and mir319. The first two target the host RNAi machinery while the third one is involved in host developmental program.

Mir168: This is a conserved miR of plant kingdom; it targets AG01 mRNA and help in establishing the level of AGO1 in a homeostatic manner. It is also induced in response to several kinds of virus infections in plants. The induction has been evidenced in N.benthamiana test plants when infected with crucifer- infecting tobacco mosaic virus (crTMV), potato virus $X$ (PVX), tobacco etch virus (TEV), similarly in Arabidopsis thaliana when infected with TCV and ribgrass mosaic virus (RMV). Sun-hemp mosaic virus (SHMV) infection in Medicago truncatula, TMV U1 and PVX infections in Solanum lycopersicum also cause drastic induction of miR168 [28]. The miR168 is also highly expressed in tobacco following infection of Cymbidium Ringspot Virus (CymRSV), in rice infected with Rice Stripe Virus (RSV) and Rice Dwarf Virus (RDV) [29], in Vitis vinifera plants infected with Grapevine Rupestris Stem Pitting associated Virus (GRSPaV) [30] and tomato infected with cucumber mosaic virus (CMV) [31]. In most of these infection events, the host AGO1 mRNAs are also up-regulated but as a result of miR168-AG01 interactions, AGO1 protein levels are always decreased. The miR168 pre-miR generally exist in three metastable states because of the sequence content and thus eventually many different isomeric forms of miR168 are processed. The various isomers have differing affinities for various AGOs. For example, a duplex with a 22-nt guide strand exhibits strikingly preferential affinity for AGO10, the closest AGO1 paralog. The 22-nt miR168-AG010 complex antagonizes AGO1 accumulation in part via "transitive RNAi", a silencing-amplification process, to maintain appropriate AGO1 cellular homeostasis [32]. The viral RNAi suppressors also contribute in up-regulation of miR168 and AGO1 mRNAs. The phenomena of miR168 up-regulation and consequent down-regulation of AGO1 protein level seem to be ubiquitous event in plant-virus interactions [33]. Though the exact cause of miR168 up-regulation has not been ascertained yet, several mechanisms can be postulated. Most of the virus infections are associated with induction of abscisic acid (ABA). The promoter of miR168 harbors ABA-response elements (ABRE) and thus miR168-priRNA could be induced [34]. Moreover, some of the viral RNAi suppressors also interfere in the processing of mature miRs. The RSV encoded NS3 protein interacts with rice miRNA biogenesis factor OsDRB1, increasing the accumulation of many miRs including miR168. Such increased accumulation facilitates RSV infection in rice [29]. As AGO1 protein plays the major antiviral role, its down-regulation compromises host defense and sensitizes the host towards virus infection. Conversely, it is expected that the virus resistance could be brought out by down-regulating the activity of miR168. In the case of RSV and RDV infecting rice plants, miR168 induction is also accompanied by over-expression of AGO proteins like AG018. The over-expressed AG018 sequesters majority of miR168 and thus releases AG01 proteins to carry out its antiviral role. In the similar vein of argument, a broad 
spectrum transgenic virus resistance in rice has been achieved by over-expression of AG018 and consequent sequestration of miR168 [35].

miR6026: When tomato is infected by viruses like PVX, TMV, CMV etc., miR6026 is induced in an indirect manner as tomato DCL2 (especially DCL2b) is over-expressed following virus invasion. The DCL2 protein (and not DCL1), in turn, processes increased accumulation of miR6026. This miR also targets DCL2a-, DCL2b- and DCL2dmRNAs for slicing at their 5' UTR region to generate secondary phasiRNA [36]. The act of slicing by miR and subsequent dicing using the phasiRNAs weakens tomato DCL2. As discussed earlier, the leader antiviral factor in tomato is DCL2 (DCL4 playing the subsidiary role) and thus the antivirality is compromised. The DCL2 mutants of tomato are also highly prone to virus infections, a fact in agreement with the proviral role of miR6026. This miR also produces phasiRNAs from the disease resistance gene TM2 which provide resistance against TMV, thus weakening TM2 and helping virus invasion. So, if miR6026 activity could be down-regulated, virus would be combated out. In their elegant experiment, Wang et al. allowed to express target mimic RNA of miR6026 in tomato to lock the miR in repressed state and thus achieved resistance against PVX and TMV [37].

miR319: This miR is also conserved in plants but does not affect RNAi factors. This miR is highly accumulated during leaf curl virus invasions in solanaceous crops [38], Rice Ragged Stunt Virus (RRSV) infection in rice, and also Rice Black Streak dwarf Virus (RBSdV) in wheat etc. [39]. With the progress of leaf curl symptoms and accumulation of higher virus titers, miR 319 levels in the infected leaves keeps on increasing [38]. In the case of RRSV infection in rice, the increased amount of miR319 decreases the level of TCP21 gene expression. This reduction is associated with decreased amount of jasmonic acid (JA) biosynthesis and reduced JA-signaling pathway proteins. As JA stands for host defense, accumulated miR319 helps virus invasions. When this miR is over-expressed in rice by transgenic means, the transgenic plant becomes highly sensitive to RRSV. Similarly, transgenic down-regulation of miR319 or transgenic over-expression of miR-resistant TCP21 leads to virus resistance. In another instance, the virulent form of CMV, i.e., CMV-Fny causes higher expression of miR319 compared to the mild CMV strain, CMV-LS [40]. Thus it is evident that viruses use miR319 to their benefits in many instances $[39,40]$.

The co-evolutionary battle between the hosts and viruses dates probably back to a billion years ago and is ever-expanding. Plants fend off viruses using the RNAi factors while viruses trick the RNAi factors by encoding RNAi suppressors as a measure of counter defense strategy. The hosts neutralize the viral counter-defense by developing the counter-counter defense and the viruses, in turn, also employ means to defeat the hosts further. Using forces of mutation and recombination, viruses generate variants and the virulent forms are selected in the face of host-restrictions. The virulent viral forms are eventually tamed by matched changes in the host genomes. The ongoing battle has thus probably shaped plant evolution and the antiviral RNAi genes have evolved much faster than the rest of genes of plant genomes. Similarly, the viral genes of RNAi suppressors have outmatched other viral genes in the profiles of evolutionary changes [41]. In the backdrop of this ever-expanding battle, some interesting postulates could be observed as follows. Recently Aguado et al., have nicely shown how Drosha have evolved in the face of viral evasions [42]. Drosha analogues of plants are the DCLs and these are too many in structures and functions compared to their animal counterparts. The main antiviral mechanisms of Plants are RNAi-based, whereas animals have many other mechanisms including the antibody-mediated immunity. Extending the arguments provided by Aguado et al., it can be assumed that the DCLs probably have duplicated many times in plants to cope up with the viral pressure and diverged in the course of evolution assuming unique as well as overlapping functional features. So plant DCLs have probably been shaped by viral evolution. Secondly, we have earlier 
mentioned how the hosts counter-counter defense (CCD) works and following the logic of co-evolution, it may be worthwhile to look for viral proteins that interact with the CCD proteins to diminish the activity of the latter group of proteins. Next, it has been recently shown that DCL3/ DCL4 proteins also make miRs which are longer in size (2325 mers) but these miRs are more environmentally adaptive [43]. We have already pointed out the role of 22mer sized miR 6026 and possibly the roles of these longer version of miRs will emerge further in future to deal with the viral stress. As the plants have evolved to deal with viral stress, plants encode not only the antiviral RNA-silencing factors but also a few factors that make them hyper-susceptible to viruses directly. For example, the RDR1 protein of Nicotiana tabacum was shown to suppress RNA silencing and cause hypersensitivity to a wide range of viruses like PPV, CMV, PVX, PVY, TRV, TMV, ToMV etc. [44]. Let's now turn our attention to another form of arms race. The Tm1 resistance gene of tomato binds to RdRP of Tomato Mosaic virus (ToMV) and thus restricts viral replication. In an elegant study, Ishibashi et al., have revealed structures of the complex between Tm1 and RdRP of ToMV, discovering the atomistic details for the recognition- evasion arms race between ToMV and Tm1. The Tm1 recognition by RdRP of ToMV, viral adaptive evasion of recognition, host counter-adaptation, and viral counter-counter adaptation are revealed from the complex structures of variants of Tm1 and viral RdRPs [45]. Similar structural studies between RNAi suppressors and interacting RNAi factors need be carried out in future to record the footprints of reciprocating rounds of the ongoing battle between the viruses and plants.

\section{References}

1. Agrawal N, Dasaradhi PV, Mohmmed A, Malhotra P, Bhatnagar RK, et al. RNA interference: biology: mechanism: and applications. Micro Mol Biol Rev. 2003; 67: 657-685. Ref.: https://goo.gl/yZVjzk

2. Koonin EV, Dolja VV, Krupovic M. Origins and evolution of viruses of eukaryotes: The ultimate modularity. Virol. 2015; 479-480: 2-25. Ref.: https://goo.gl/wsJprG

3. Ma A, Mondragón RJ. Rich-Cores in Networks. PLoS One. 2015; 10: 1-13. Ref.: https://goo.gl/5iN9iU

4. Rajewsky, Nikolaus, Jurga, Stefan, Barciszewski. In Plant Epigenetics. RNA Tech. 199-230. Ref.: https://goo.gl/twwyMH

5. Yang Z, Li Y. Dissection of RNAi-based antiviral immunity in plants. Curr Opin Virol.2018; 32: 88-99. Ref.: https://goo.gl/eNnTC8

6. Llave $\mathrm{C}$. Virus-derived small interfering RNAs at the core of plant-virus interactions. Trends Plant Sci. 2010; 15: 701-707. Ref.: https://goo.gl/HbDbgP

7. Wang $X B$, Jovel J, Udomporn $P$, Wang $Y$, Wu Q, et al. The 21-Nucleotide, but Not 22-Nucleotide, Viral Secondary Small Interfering RNAs Direct Potent Antiviral Defense by Two Cooperative Argonautes in Arabidopsis thaliana [W][OA]. Plant Cell. 2011; 23: 1625-1638. Ref.: https://goo.gl/qFWGKq

8. Brosseau C, El Oirdi M, Adurogbangba A, Ma X, Moffett P. Antiviral Defense Involves AGO4 in an Arabidopsis-Potexvirus Interaction. Mol Plant-Microbe Int. 2016; 29: 878-888. Ref.: https://goo.gl/vyJsNT

9. Chen C, Zeng Z, Liu Z, Xia R. Small RNAs, emerging regulators critical for development of horticultural traits. Hort Res. 2018; 5: 62-75. Ref.: https://goo.gl/yVk2Ap

10. Ramesh SV, Sahu PP, Prasad M, Praveen S, Pappu HR. Geminiviruses and Plant Hosts: A closer examination of molecular arms race. Viruses. 9: 256-276. Ref.: https://goo.gl/raiHSB

11. Taochy C, Gursanscky NR, Cao J, Fletcher SJ, Dressel U, et al. A Genetic Screen for Impaired Systemic RNAi Highlights the Crucial Role of DICER-LIKE 2. Plant Physiol. 2017; 175: 1424-1437. Ref.: https://goo.gl/6dd2ou

12. Qin C, Li B, Fan Y, Zhang X, Yu Z, et al. Roles of Dicer-Like Proteins 2 and 4 in Intra- and Intercellular Antiviral Silencing. Plant Physiol. 2017; 174: 1067-1081. Ref.: https://goo.gl/fXhm5m

13. Guo Z, Lu J, Wang X, Zhan B, Li W, et al. Lipid flippases promote antiviral silencing and the biogenesis of viral and host siRNAs in Arabidopsis. Proc Acad Natl Sci (USA). 2017; 114: 1377-1382. Ref.: https://goo.gl/VzaYr8

14. Guo Z, Wang XB, Wang Y, Li WX, Gal-On A, et al. Identification of a New Host Factor Required for Antiviral RNAi and Amplification of Viral siRNAs. Plant Physiol. 2017; 176: 1587-1597. Ref.: https://goo.gl/qv7qfL 
15. Simón-Mateo C, García JA. MicroRNA-guided processing impairs Plum pox virus replication, but the virus readily evolves to escape this silencing mechanism. J Virol. 2006; 80: 2429-2436. Ref.: https://goo.gl/TLb9on

16. Deng $\mathrm{P}$, Muhammad $\mathrm{S}$, Cao M, Wu L. Biogenesis and regulatory hierarchy of phased small interfering RNAs in plants. Plant Biotech J. 2018; 16: 965-975. Ref.: https://goo.gl/6y4BqU

17. Bivalkar-Mehla S, Vakharia J, Mehla R, Abreha M, Kanwar JR, et al. Viral RNA silencing suppressors (RSS): novel strategy of viruses to ablate the host RNA interference (RNAi) defense system. Virus Res. 2011; 155: 1-9. Ref.: https://goo.gl/ovBczc

18. Zhao JH, Hua CL, Fang YY, Guo HS. The dual edge of RNA silencing suppressors in the virus-host interactions. Curr Opin Virol. 2016; 17: 39-44. Ref.: https://goo.gl/QkS6Hz

19. Csorba T, Kontra L, Burgyán J. Viral silencing suppressors: Tools forged to fine-tune host-pathogen coexistence. Virol. 2015; 479-480, 85-103. Ref.: https://goo.gl/mNuQoY

20. Pérez-Cañamás $M$, Hernández $C$. Key importance of small RNA binding for the activity of a glycinetryptophan (GW) motif-containing viral suppressor of RNA silencing. J Biol Chem. 2015; 290: 31063120. Ref.: https://goo.gl/Ankwiw

21. Pertermann R, Tamilarasan S, Gursinsky T, Gambino G, Schuck J, et al. A Viral Suppressor Modulates the Plant Immune Response Early in Infection by Regulating MicroRNA Activity. mBio. 2018' 9: e00419-18. Ref.: https://goo.gl/SL7tWw

22. Incarbone $M$, Zimmermann $A$, Hammann $P$, Erhardt $M$, Michel $F$, et al. Neutralization of mobile antiviral small RNA through peroxisomal import. Nat Plant. 2017; 3: 17094. Ref.: https://goo.gl/oL3w2K

23. Li F, Wang A. RNA decay is an antiviral defense in plants that is counteracted by viral RNA silencing suppressors. PLos Pathog. 2018; 14: e1007228. Ref.: https://goo.gl/anRxTq

24. Pumplin N, Voinnet $O$. RNA silencing suppression by plant pathogens: defence, counter-defence and counter-counter-defence. Nat Rev (Microbiol). 2013; 11: 745-760. Ref.: https://goo.gl/6yYLYd

25. Chen L, Yan Z, Xia Z, Cheng Y, Jiao Z, et al. A Violaxanthin Deepoxidase Interacts with a Viral Suppressor of RNA Silencing to Inhibit Virus Amplification. Plant Physiol. 2017; 175:1774-1794. Ref.: https://goo.gl/sedWUc

26. Shen Q, Hu T, Bao M, Cao L, Zhang H, et al. Tobacco RING E3 Ligase NtRFP1 Mediates Ubiquitination and Proteasomal Degradation of a Geminivirus-Encoded BC1. Mo Plant. 2016; 9: 911-925. Ref.: https://goo.gl/4HSfhS

27. Jeon EJ, Tadamura K, Murakami T, Inaba JI, Kim BM, et al. rgs-CaM Detects and Counteracts Viral RNA Silencing Suppressors in Plant Immune Priming. J Virol. 2017; 91-e00761-17. Ref.: https://goo.gl/D5UYNM

28. Várallyay E, Válóczi A, Agyi A, Burgyán J, Havelda Z. Plant virus-mediated induction of miR168 is associated with repression of ARGONAUTE1 accumulation. EMBO J. 2010; 29: 3507-3519. Ref.: https://goo.gl/LXHHCa

29. Zheng L, Zhang C, Shi C, Yang Z, Wang Y, et al. Rice stripe virus NS3 protein regulates primary miRNA processing through association with the miRNA biogenesis factor OsDRB1 and facilitates virus infection in rice. PLos Pathog. 2017; 13: e1006662. Ref.: https://goo.gl/uxY2XZ

30. Pantaleo V, Vitali M, Boccacci P, Miozzili L, Cuozzo D, et al. Novel functional microRNAs from virusfree and infected Vitis vivifera plants under water stress. Scientific Reports. 2016; 6: 20167-20180. Ref.: https://goo.gl/LnkqYi

31. Feng J, Liu S, Wang M, Lang Q, Jin C. Identification of microRNAs and their targets in tomato infected with Cucumber mosaic virus based on deep sequencing. Planta. 2014; 240: 1335-1352. Ref.: https://goo.gl/nLh15N

32. Iki T, Cléry A, Bologna NG, Sarazin A, Brosnan CA, et al. Structural Flexibility Enables Alternative Maturation, ARGONAUTE Sorting and Activities of miR168, a Global Gene Silencing Regulator in Plants. Mol Plant. 2018; 11: 1008-1023. Ref.: https://goo.gl/xknqL2

33. Várallyay E, Havelda Z. Unrelated viral suppressors of RNA silencing mediate the control of ARGONAUTE1 level. Mol Plant Pathol. 2013; 14: 567-575. Ref.: https://goo.gl/aqxqUd

34. Noman A, Aqeel M, Deng J, Khalid N, Sanaullah T, et al. Biotechnological Advancements for Improving Floral Attributes in Ornamental Plants. Front Plant Sci. 2017; 8: 1760-1769. Ref.: https://goo.gl/x7nhm6 
35. Wu J, Yang Z, Wang Y, Zheng L, Ye R, et al. Virus inducible Argonaute 18 confers broadspectrum virus resistance in rice by sequestering a host microRNA.eLIFE. 2015; 4: e05733. Ref.: https://goo.gl/voDgjb

36. Kravchik M, Sunkar R, Damodharan S, Stav R, Zohar M, et al. Global and local perturbation of the tomato microRNA pathway by a trans-activated DICER-LIKE 1 mutant. J Exp Bot. 2014; 65: 725-739. Ref.: https://goo.gl/xcb58y

37. Wang Z, Hardcastle TJ, Canto Pastor A, Yip WH, Tang S, et al. A novel DCL2-dependent miRNA pathway in tomato affects susceptibility to RNA viruses. Genes and Dev. 2018; 32: 1155-1160. Ref.: https://goo.gl/Jrii6P

38. Naqvi AR, Haq QMR, Mukherjee SK. MicroRNA profiling of tomato leaf curl new delhi virus (tolcndv) infected tomato leaves indicates that deregulation of miR159/319 and miR 172 might be linked with leaf curl disease. Virol J. 2010; 7: 281-296. Ref.: https://goo.gl/SoXzjG

39. Zhang C, Ding Z, Wu K, Yang L, Li Y, et al. Suppression of Jasmonic Acid-Mediated Defense by ViralInducible MicroRNA319 Facilitates Virus Infection in Rice. Mol Plant. 2016; 9: 1302-1314. Ref.: https://goo.gl/TCkmMe

40. Cillo F, Mascia T, Pasciuto MM, Gallitelli D. Differential effects of mild and severe Cucumber mosaic virus strains in the perturbation of MicroRNA-regulated gene expression in tomato map to the 3 sequence of RNA 2. Mol Plant-Microbe Int. 2009; 22: 1239-1249. Ref.: https://goo.gl/bgTdAi

41. Obbard DJ, Gordon KH, Buck AH, Jiggins FM. The evolution of RNAi as a defence against viruses and transposable elements. Phil Trans R Soc B. 2009; 364: 99-115. Ref.: https://goo.gl/3CEeFo

42. Aguado LC, Schmid S, May J, Sabin LR, Panis M, et al. RNase III nucleases from diverse kingdoms serve as antiviral effectors. Nature. 2017; 547: 114-117. Ref.: https://goo.gl/HoRmYN

43. Vazquez F, Blevins T, Ailhas J, Boller T, Meins F, Jr. Evolution of Arabidopsis MIR genes generates novel microRNA classes. Nucl Ac Res. 2008; 36: 6429-6438. Ref.: https://goo.gl/bWbgvQ

44. Ying XB, Dong L, Zhu H, Duan CG, Du QS, et al. RNA-Dependent RNA Polymerase 1 from Nicotiana tabacum Suppresses RNA Silencing and Enhances Viral Infection in Nicotiana benthamiana. Plant Cell. 2010; 22: 1358-1372. Ref.: https://goo.gl/snkReA

45. Ishibashi K, Kezuka $Y$, Kobayashi $C$, Kato M, Inoue $T$, et al. Structural basis for the recognitionevasion arms race between Tomato mosaic virus and the resistance gene Tm-1. Proc Natl Acd Sc. U S A. 2014; 111: E3486-E3495. Ref.: https://goo.gl/vjZTfo 